Dickinson, David L. (2002), A Bargaining Experiment to Motivate Discussion on Fairness. Journal of Economic Education, 33(2): pp. 136-51. (Spring 2002) Published by Taylor \& Francis (ISSN: 2152-4068) DOI:

$10.1080 / 00220480209596463$

\title{
A bargaining experiment to motivate discussion in fairness
}

David L. Dickinson

\begin{abstract}
The author presents a classroom version of the popular research game called the Ultimatum Game. Researchers are placing growing importance on how fairness affects behavior, and this experiment provides a useful, fun, and engaging way in which a day or two of class time can be spent on the topic. The appendix contains all of the materials necessary to conduct this experiment, and the experiment can highlight several items of interest for the instructor. First, different individuals place different subjective weights on concerns for fairness versus money. Second, theories that incorporate concerns for fairness into agents' preferences can often explain behavior better than those that do not. Finally, when it is relatively cheap to purchase fairness (or equality) individuals purchase more of it. The classroom results can motivate discussion of a downward sloping demand curve for fairness.
\end{abstract}


A variety of research on simple bargaining behavior shows that outcomes are not always consistent with pure self-interested decisionmaking. Fairness considerations have been offered as an explanation for at least some of these results. Undergraduate economics students are usually quick to note that individuals may not behave like homo economicus. It is therefore not surprising that fairness or equity of allocations often arises in classroom discussion of various market outcomes. As the economic literature on fairness research continues to grow, economists should hope that at least a small portion of this research spills over into our classrooms. In this article, I outline a simple classroom bargaining experiment that yields interesting insights and promotes classroom discussion on how concerns for fairness affect economic decisions. Because simple two-person bargaining is the foundation of many more complicated bargaining environments (and even policy decisions), this experiment would be useful in many applied courses as well as in principles and introductory level courses. This article provides all the tools necessary to conduct the experiment in class (including instructions and relevant paperwork in the appendix). I also suggest some discussion topics that can stem from this experiment and present some of my classroom data.

\section{BACKGROUND}

Literature about a bargaining game called the Ultimatum Game (and a related game called the Dictator Game) has been developed in the last 20 years. In the Ultimatum Game (Guth, Schmittberger, and Schwarze 1982), a proposed division of an amount of money-the pie-is made by one individual, the proposer, and a second individual, the responder, either accepts (in which case the division is carried out) or rejects the offer (in which case both subjects receive zero). In the Dictator Game, the responder cannot reject any offer made. Note that the self-interested responder concerned only with money outcomes (i.e., homo economicus) would be willing to accept even the smallest allowable offer in the Ultimatum Game, which would induce the proposer to offer the minimal amount. This is the Nash equilibrium prediction for agents with preferences only over their own monetary payoffs.[1]

Several consistencies can be noted in the large number of research studies that focus on different variants of these pie-splitting games.[2] First, proposers in the Ultimatum Game typically offer substantially more than the minimal amount. The modal offer is 50 percent of the pie, and the mean offer is between 25 percent and 50 percent of the pie. Such behavior led many researchers to claim that concerns for fairness were driving results. In fact, the Dictator and Ultimatum games are compared in Forsythe et al. (1994) to separate offers arising from fairness from those arising from strategic considerations (i.e., positive offers in the Dictator Game would result from concerns for fairness, and the difference in offer percentage between the two games represents the fear of rejection). Although substantially more proposers keep all of the pie in the Dictator Game, many still do not. It is probably the case that some of the observed generosity in such experiments is the result of a lack of anonymity that triggers social norms of behavior. Hoffman et al. (1994) present Dictator experiments conducted as doubleblind (subject-subject and subject-experimenter anonymity), which generate the highest levels of self-interested behavior observed in Dictator games. 
All of this indicates that individuals do not necessarily behave as the traditional theories predict. The term fairness can be thought of as a blanket term that encompasses many different types of other-regarding preferences such as altruism, reciprocity, revenge, and so forth. The point of this classroom experiment is not to debate what the term fairness means-your students will do that for you after the experiment-but to use a classroom version of this classic two-person Ultimatum Game to draw out the distinction between self-interested behavior and behavior displaying concerns beyond money outcomes.

\section{THE EXPERIMENT}

This experiment involves a repeated version of the Ultimatum Game among randomly rematched pairs of students.[3] Practically speaking, instructors will probably not conduct exhaustive data analysis and comparisons of behavior across multiple Ultimatum Games for a classroom experiment. However, the merit for the instructor of this experiment is that it is relatively easy to summarize the data and to motivate discussion of fairness and even the tradeoff between fairness and efficiency. Because this experiment involves physically transferring messages back and forth between proposers and responders, it is probably best for classes of 40 students or fewer (a teaching assistant may prove useful for this experiment). I have, however, successfully conducted this experiment in a class of over 100 by creating decisionmaking teams of 3 individuals to play the role of I experimental subject.

The issue of how properly to motivate students for in-class experiments is a controversial one. Three possible options are to announce that earnings are hypothetical, to randomly pay one subject his or her experimental earnings (it motivates students but is not overly costly to the instructor), and to pay subjects in terms of classroom or extra-credit points. The choice is up to each instructor, but the potential drawbacks of each method should be noted. [4] First, with hypothetical earnings, the potential exists that students will not take decisions seriously, thereby creating a "noisy" set of classroom data and/or disinterested students. Second, the option to pay even one randomly chosen subject involves a monetary cost, either out of the instructor's pocket or out of departmental funds (and, hence, the need to justify the expense). Finally, awarding classroom points raises the issue of . . . fairness. Experimental earnings are not independent of the random pairings of bargainers, their instructor needs to be prepared to justify the method to the students.

I follow the practice of ranking outcomes of the proposers and the responders (these are the two distinct roles in this experiment, which are discussed in the next section) separately for terms of whatever material incentive is being offered because one group of subjects may typically receive higher experiment payoffs than the other. On the other hand, the incentives are most similar to an experiment with all cash payoffs if subjects are rated together as one group. There is a tradeoff here between how students perceive the rewards as fair and unfair and how close the instructor can mirror a cash incentive experiment with classroom points. I have found it easiest to rank students based on experimental roles and address the issue of payoffs as part of the postexperiment discussion. Some instructors may also be concerned that grades would be, in small part, determined by something that may or may not reflect the students' acquisition of 
key course material. I believe that useful classroom discussion can follow regardless of the method used, as the tradeoffs present in the simple game are transparent to most students.

\section{PROCEDURES}

The instructor should divide the class so that half of the students are proposers, and half are responders in the experiment. If there is an odd number of students, the odd student can serve as an administrative aid in the experiment. It is easiest if students do not change roles during the experiment, although simple modifications of the design may be used. Half of the students should receive the Instructions for Player A (the proposers) along with a preassigned identification number in the top right-hand corner and the other half should receive Instructions for Player B (the responders). (These instructions are reproduced in the appendix.) The decision sheet that accompanies each set of instructions allows students to keep track of their decisions, and it allows the instructor to keep track of class results for discussion or extra-credit point payment. The number of rounds is a function of the length of the class period and of whether discussion is part of the same class period, but a 50-minute class should be enough time for a classroom of 40 students to receive and read the instructions and bargain for 10 rounds.

The instructor should then use small strips of paper to transfer messages to and from bargaining counterparts for each round (see the appendix). The instructor writes the size of the pie for the current round on the strip of paper before handing it to the proposer. A proposer should write his or her identification number at the top of the strip of paper. Proposers make a dollar amount proposal to a responder by first filling out the pie size and the proposal on the decision sheet, and then the proposer makes the proposal on the strip of paper. The instructor then collects all proposer offers and distributes them in random fashion to the responders. Each responder fills in the pie size and offer on his or her decision sheet, and the responder then makes an acceptance or rejection decision on the decision sheet. At this point, the responder writes the same accept/reject decision on the message strip, and the instructor collects all strips and gives them back to the appropriate proposer, using the identification number. When round one is complete, the instructor double-checks that everyone knows what is going on and has fully understood the interaction and how to calculate earnings for the round. Note that the Decision Sheets given in the appendix also ask additional hypothetical questions, which can generate useful data on dictator decisions and minimum acceptance thresholds.

All subsequent rounds proceed in the same manner as round one with the following differences. The size of the pie is changed in each round in random fashion, sometimes increasing the pie size and sometimes decreasing it. The instructor can preannounce the entire pie-size distribution to the students so that they are aware of what constitutes a small or large pie for the experiments Also, the instructor should avoid re-pairing the same two students, if at all possible, and should announce that students are not rematched with the same individual twice.[6] This eliminates the potential for the students' decisions to be based on play of a multi-stage game rather than a one-shot game. Students typically want to voice their displeasure of counterpart behavior during the experiment, and I have consistently had to deal with students voicing strategic threats during the course of the experiment. Depending on the control that the 
instructor has over limiting the students' communications, a useful suggestion might be to physically separate proposers and responders (e.g., use two adjacent rooms or locate half of the students in the hallway). I have not attempted physical separation of proposers and responders but have instead opted for using credible threats as to the consequences of any sort of communication during the experiment. If students are physically separated, the instructor should attempt to have a monitor or teaching assistant present with each group because students may attempt to collude to procure better outcomes. In any event, communication during the experiment can not only affect decisions, but it can also limit the number of rounds that the class completes in one period.

At the end of the final round, the instructor should make sure that all students have correctly and completely filled out their decision sheets before turning them in. Cheating and incorrect student record keeping are realities that may affect a small amount of the data. More or less effort can be expended by the instructor to alleviate these concerns. I generally check for math errors or other suspicious entries ex poste after having preannounced that any record sheet found to contain entry errors of any sort are ineligible for receiving extra-credit points (or cash).' At this point, a general discussion can follow if time permits, or the discussion can wait until the next class period if the instructor either runs out of time or desires to compile and prepare the classroom data for discussion (and announce top earning proposers and responders for extracredit points, for example). In any event, the instructor should prepare the decision sheets with space for plenty of bargaining rounds, should have an appropriate number of message strips on hand, and should take the time to make sure that everyone comprehends the experimental instructions.

Of course, an instructor may not wish to dedicate an entire class period to conducting an experiment of several rounds. A simplified version of this exercise would be a one-shot (i.e., one round) game played at the very end of class. If conducted as a one-shot game, the instructor should have all pairs bargaining over the same pie size, because different pie sizes raise the issue of how to allocate extra-credit points or cash based on a one-shot game when different pairs play for different stakes. Even as a fixed-stakes one-shot game, this experiment can be used to raise many of the discussion topics highlighted in the next section, and it would do so with less time commitment and less (potential) instructor anxiety, compared with a multiround experiment.

\section{DISCUSSION TOPICS}

Some students may view the experiment as a contrived game. However, the instructor can magnify the relevance of the experiment by highlighting real-world bargaining situations that somewhat approach simple ultimatum bargaining. The fact that the Ultimatum Game consists of one offer and a rejection or acceptance implies that it is most similar to final-stage negotiations of various sorts. Relevant examples may include a union's acceptance or rejection of a firm's last contract offer-the offer can be viewed as a percentage of the profit pie offered to the union. Union rejection of the last offer may lead to a costly strike, which is simulated by a zero payoff to each player. Another example would be new automobile purchases. Often, informed buyers 
know with reasonable certainty what the dealer's profit on the vehicle is. A last offer (from either buyer or dealer) can be thought of as an offer of a percentage of the dealer's profit pie. Useful examples can also be abstracted from the division of a monetary pie. Such would be the case with negotiations for peace between two disputing countries, which can be considered a piesplitting game (especially if the issue is literally over how to divide territories, such as we see in the dispute over Jerusalem between Israel and the Palestinian Liberation Organization). Rejection of a final offer can often lead to an escalation of violence or outright war, both of which are costly outcomes somewhat simulated by the destruction of the pie in the Ultimatum Game.[8]

Another useful way to promote discussion and focus students on behavioral hypotheses is to point out different economic theories and show the class how it behaved relative to the predictions of those theories. I highlight two theories for comparison, but they obviously do not exhaust all possibilities. First, the predictions derived from assuming that individuals care only about money are easily discredited from the aggregate data (although not necessarily by each individual's behavior). I call this theory's prediction the homo economicus hypothesis. An interesting competitor theory can be called the fairness hypothesis, which can be described as follows: Responders will reject what are considered unfair offers and accept those considered fair. Students are willing to pay to punish unfair proposers. Proposers are then constrained to make proposals considered fair by the responders. In addition, consider that responders may be willing to accept a smaller percentage of the pie as the size of the pie grows. This is a testable hypothesis, although ex poste discussion would have to be speculative if a oneshot game is conducted.

The fairness hypothesis stems from the predictions of the Rabin (1993) theory; and the application to the Ultimatum Game and consequent instructional diagram are in Dickinson (2000). Students need not be shown the derivation of Figure 1, but the instructor should explain the basic assumptions of the theory that leads to Figure 1: individuals care about both money and fairness, and fairness in this model is such that individuals want to reciprocate both kind and unkind behavior.[9] Again, any theory of fairness yielding a testable implication will work for discussing and scrutinizing outcomes, but I have chosen this particular theory both because of its intuitiveness and the resulting instructional diagram that captures much of the model in one simple graph, which makes it easier for students to remember testable implications.

The horizontal axis in Figure 1 measures the percentage of the pie offered by the proposer to the responder. The vertical axis measures the size of the pie, $\mathrm{X}$, multiplied by the relative weight the individual places on money versus fairness components of his utility function (alpha is the weight placed on the money portion of the utility function, and so [ 1 - alpha] is the weight placed on the fairness portion of the utility function). The convex curve in Figure 1 is the decision boundary of the responders, which also affects proposers' offers because the assumption is that proposers are aware of the fact that responders decide according to Figure 1 . All offers to the northeast of the curve will be accepted, and those southwest of the curve will be rejected. It is apparent from Figure 1 that offers of 50 percent or more of the pie should always be accepted, whereas offers of 0 percent should always be rejected. The basic intuition of the fairness theory is that proposers want to keep as much of the pie as possible while still being considered fair by 
the responder, and the responder's concept of fair is a function of the stakes of the game. The responder accepts or rejects to reciprocate his perception of the fairness of the offer.[10] Perfectly informed proposers would make proposals on the boundary curve in Figure 1, but actual behavior would at best approximate such a curve.

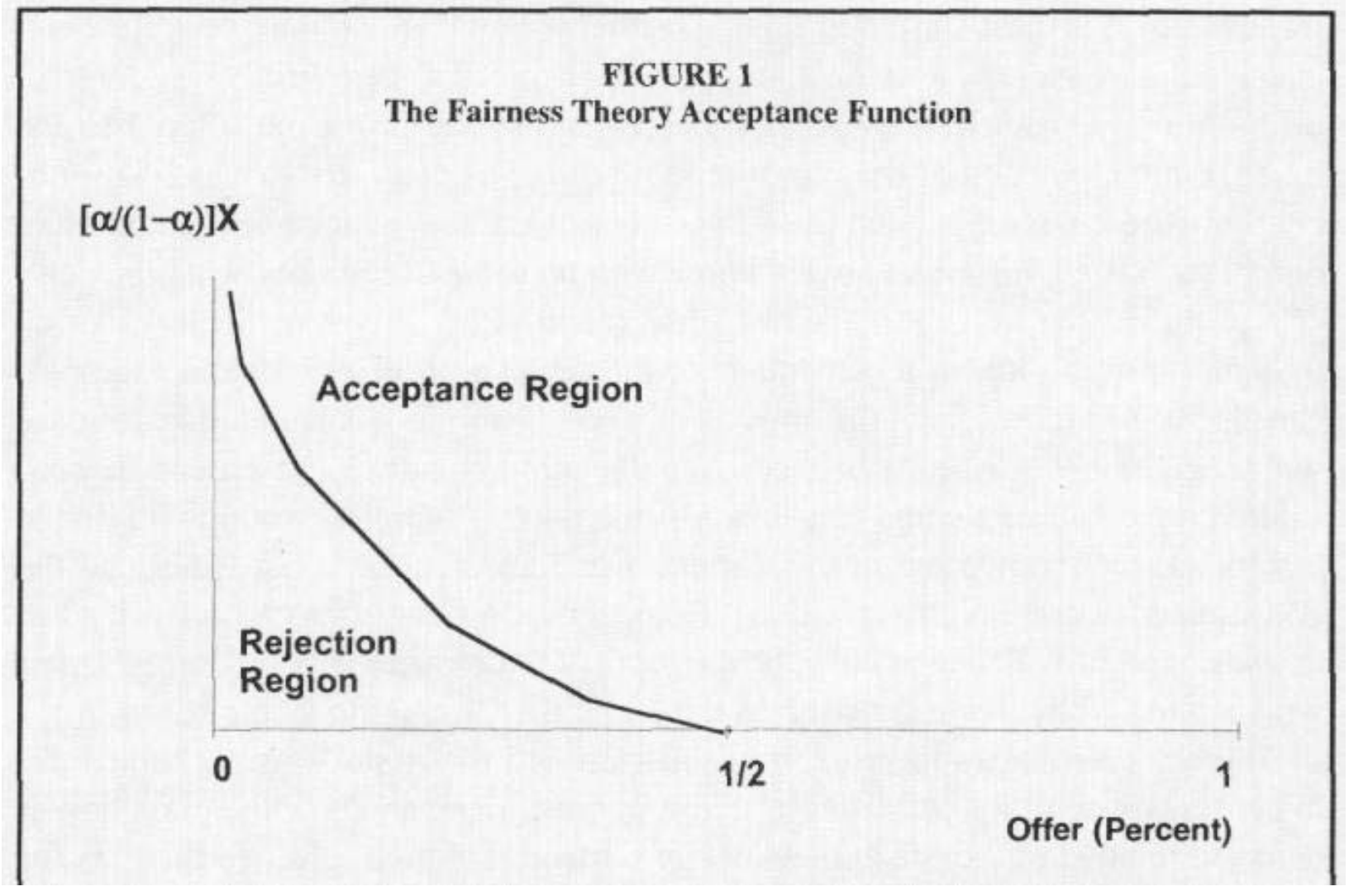

Proposers do not actually know what the responders' notion of fairness is. The predictions derived from the Rabin (1993) theory are based on a proposer's belief about the strategy that the responder will use. As such, in a multiround experiment, a proposer may make offers based, in part, on the history of responses to his offers. In reality, social norms of behavior are important in shaping decisions and can be used as another useful discussion topic following a multiround experiment.

For offers between 0 and 50 percent of the pie, Figure 1 shows the fairness prediction that responders who care relatively more about money are more likely to accept smaller percentage offers than those who care relatively less about money, holding the stakes of the game constant. Similarly, holding the person constant (i.e., (alpha constant), the larger the stakes of the game, the more likely an individual will accept smaller percentage offers. When individuals in each round are rematched, an interesting observation is that the higher threat of rejection by those who care more about money creates a public good for all responders. Responders who care less about money-and more about fairness-can then free-ride off the higher offers generated by others' threat of rejection.[11] For proposers, who are assumed to be aware of the 
responder decision process, offer percentages should decline for larger pie sizes (Figure 1 implies that responders would accept smaller offers).

Note that an "efficient" outcome in the Ultimatum Game is acceptance of any offer, and so (1 alpha) could also be considered a measure of the price of efficiency. Hence, a higher price of efficiency (a lower point on the vertical axis), ceteris paribus, means that a given individual is more likely to forego relatively expensive efficiency in favor of relative inexpensive fairness and reject a given offer. In essence, this says that individuals will purchase more fairness when it is cheaper (in terms of foregone material outcomes). Numerous dimensions of interest to the instructor are shown in Figure 1. Andreoni and Miller (2001) presented some related research in which the relative price of material giving is systematically manipulated in their experimental design. They show that when the relative price of material giving is low, proposers are more generous in their percentage offers to responders. Although their research captures another interesting dimension of why proposers might offer more or less to responders, the relative price of giving is not relative to fairness in their design.[12] Their results do, however, highlight that proposers have concerns beyond their own material outcomes.

\section{CLASSROOM RESULTS}

I conducted this experiment in an introductory economics class in the spring 2000 semester at Utah State University; data are shown in Figure 2 and Table 1. About 60 students participated in the 10-round experiment, and extra-credit points were awarded based on earnings rankings for the top five proposers and responders-the maximum points earned were about a half a letter grade on one midterm exam. In addition to the basic Ultimatum Game, I also asked proposers and responders to answer an additional hypothetical question (see instructions in appendix). Proposers were asked to state what their dictator offer would be, and responders were asked to state the minimum amount they would be willing to accept for a given pie size.

As shown in Table 1, individuals do not behave as homo economicus: responders reject positive offers, and even hypothetical dictators would not keep everything.[13] The behavior from this class is also roughly in line with the fairness hypothesis. This can be noted in Figure 2, which shows an inverse relationship between acceptable percentage offers and the pie size-an inverse relationship predicted in the fairness hypothesis of Figure 1 (although the axes are flipped between the two graphs).[14] Further, the data in Table 1 show that if the threat of rejection were removed, proposers would offer much less. This highlights the importance of some strategic considerations in summarizing the students' behavior.[15]

Results from different classes are bound to vary, which is fine. Different outcomes underline the important point that individuals and groups of individuals are heterogeneous. Patterns of behavior, however, highlight that a rational process is motivating behavior. Some small classes in which students know each other or feel a lack of true anonymity may generate different outcomes than larger classes. I have noticed that when first-round offers start relatively high, responders may be unwilling to accept lower percentage offers than the current status quo. Responders may even attempt collusion (tacit or overt) by systematically rejecting offers in an 
attempt to establish a reputation that will generate higher future offers. A one-shot game would limit such behavior, but such strategic behavior in multiround experiments often fuel interesting discussion as well (though perhaps not as directly related to the issue of fairness)-this is noted in question 3 below.

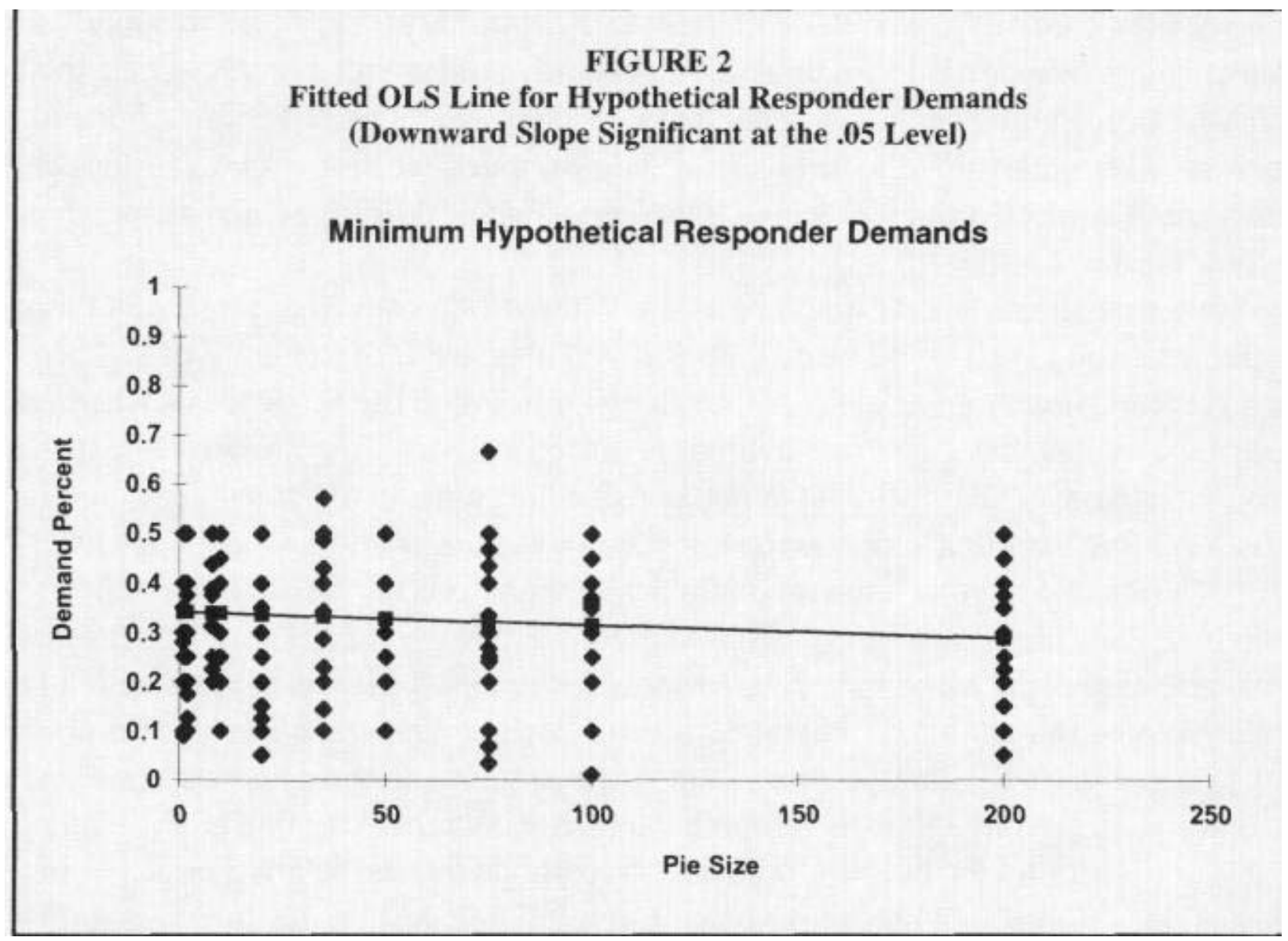


TABLE 1

Data from Classroom Experiment Averaged across All Bargainers (in percent)

\begin{tabular}{|c|c|c|c|c|}
\hline \multirow[b]{2}{*}{$\begin{array}{l}\text { Pie } \\
\text { size }\end{array}$} & \multicolumn{2}{|c|}{ Offers } & \multicolumn{2}{|c|}{ Rejection rates } \\
\hline & $\begin{array}{l}\text { Proposer } \\
\text { offer }^{\prime}\end{array}$ & $\begin{array}{l}\text { Hypothetical dictator } \\
\text { offer }^{1}\end{array}$ & $\begin{array}{l}\text { Offer } \\
\text { range }\end{array}$ & $\begin{array}{l}\text { Rejection } \\
\text { frequency }\end{array}$ \\
\hline 1 & 33 & 10 & $>50$ & 9 \\
\hline 2 & 28 & 8 & 50 & 4 \\
\hline 8 & 36 & 8 & $45-49$ & 6 \\
\hline 10 & 37 & 10 & $40-44$ & 2 \\
\hline 20 & 32 & 7 & $35-39$ & 14 \\
\hline 35 & 37 & 7 & $30-34$ & 18 \\
\hline 50 & 34 & 11 & $25-29$ & 31 \\
\hline 75 & 27 & 7 & $20-24$ & 35 \\
\hline 100 & 30 & 6 & $<20$ & 57 \\
\hline 200 & 35 & 8 & & \\
\hline
\end{tabular}

${ }^{1}$ Relationship between this variable and the pie size is statistically insignificant.

Regardless of the theories discussed after the experiment and regardless of the particular outcomes of the experiment, the following several points can inevitably be highlighted.

1. Different individuals have different preferences for fairness versus money.

2. Individuals behave as though money is not the only item of importance in preferences.

3. Lower percentage offers are usually rejected more frequently. Because a lower percentage offer of a given pie size implies a smaller monetary penalty to the responder for rejecting, it can be said that there is a downward sloping demand curve for fairness. Responders purchase more fairness when the price is relatively lower (see Table 1).

4. What portion of these results is due to altruism? Reciprocity? Strategic behavior?

Note that this experiment is amenable to many different extensions, and other items of interest can be noted and exploited in classroom discussion.[16] The instructions in the appendix, for example, include a hypothetical question that provides data for additional discussion and testing of the fairness hypothesis. Another extension would be to administer a simple quiz at the beginning of class, and then announce and assign the high scorers on the quiz to the role of proposer.[17] This would be done to test the hypothesis that merit matters in bargaining outcomes.[18] Responders may be willing to accept smaller percentages of the pie from proposers who appear to have earned the proposer role, as compared with a system of random assignment of roles-this is a testable hypothesis. A third extension might be a forced redistribution experiment in which the instructor announces the pie size, announces that a 
certain portion will be taxed from proposers and transferred to responders, and then an Ultimatum Game is played with the posttax pie. The results can be compared with the standard Ultimatum Game of the same pie size without the tax and redistribution.[19] A final extension might be to alternate the roles that individuals play in the experiment. Proposers would then become responders and vice versa. It might be interesting to compare students' behavior as responders to their behavior as proposers-these two different sides of the bargaining table often have quite different opinions of "fair" outcomes.

\section{CONCLUSION}

This article contains the tools an instructor needs to conduct a simple classroom bargaining experiment. The instruction that many undergraduates typically receive places little or no emphasis on how preferences beyond simple self-interested behavior may affect individuals' actions. The purpose of this experiment is to use experiential learning to motivate discussion of the role that fairness consideration can play in economic behavior. Given the recent growth in research on issues of fairness in bargaining, it seems natural that we, as educators, would spend a day or two in our classes to focus the students' interest on the topic of fairness. If nothing else, the experiment directs attention to the fact that different individuals place different weights on preferences for material rewards versus fairness-and it is proven through this experiment that such heterogeneity can affect real outcomes (and maybe cost the students money or points). This final fact will probably stick with the students long after the semester is over. 


\section{APPENDIX \\ Instructions (Player A)}

You will be a Player A in this experiment. You and a randomly assigned Player B will have the opportunity to earn some money. In this experiment, there is an amount of money called the "pie." Player A will offer some amount of the pie to an anonymous Player B. The amount offered can be in increments as small as one cent. If Player B accepts the offer that Player A makes, then Player B will receive that amount, and Player A will get the amount of the pie minus the amount offered to Player B. If Player B rejects the offer that Player A makes, then both Player A and Player B will receive zero and the pie will be returned to the experimenter. Again, if Player B accepts the proposed division of the pie, then the players will receive that division, but if Player B rejects the proposed division of the pie, then both players will receive nothing. Both Player A and Player B will know the size of the pie at the time to make decisions.

What was just described above is round 1 of this experiment. The experiment will actually consist of several rounds. Once the first round is over, all Players A will be reassigned to different Players B. All Players A will remain Players A and all Players B will remain Players B. You will never be re-matched with the same individual in future rounds. The size of the pie will change in each round. The pie may be smaller or larger in any given round than it was in the previous round, but it will never be the same size.

On the backside of these instructions is your decision sheet for the experiment. A preset number of rounds have been included, although the experimenter may or may not conduct that number of rounds. The experimenter will handle the exchange of messages from Players A to Players B by use of message slips of paper. At the beginning of a round, the experimenter will hand to you (as a Player A) a message slip of paper with the size of the pie (for that round) on it. At that point you should record the size of the pie on your record sheet, and record your identification number (ID \# on the back side of this page) and offer to Player B on the message slip. The experimenter will then collect the offers from Players A and randomly distribute them to Players B (i.e., you will not know which Player B your offer is given to). Players B will then record the size of the pie, and the Player A offer on his/her decision sheet, and make an accept or reject decision. This decision will be recorded both on Player B's decision sheet, as well as on the message slip. Once finished, the experimenter will then collect the message slips and return to you the appropriate Player B accept/reject decision (the ID \# system ensures that you will get back the appropriate offer and Player B decision). At that point, round 1 is finished, and Players A and $\mathrm{B}$ can record earnings for round 1 .

All subsequent rounds will be conducted similarly. Again, the only difference will be the size of the pie, and you are never paired with the same individual more than once. Your total earnings for the experiment are the sum of your earnings for each round.

If you have any questions, please raise your hand so that the experimenter can clarify any and all things for you prior to the start of the experiment. 
The shaded column is a hypothetical question that we would like you to answer. Your earnings for any given round do not depend on this answer at all. It is merely to provide additional useful information to the experimenter.

\begin{tabular}{|l|l|l|l|l|l|}
\hline & Pie size & $\begin{array}{c}\text { Actual offer } \\
\text { you are } \\
\text { making to } \\
\text { Player B }\end{array}$ & $\begin{array}{c}\text { What would } \\
\text { you offer if } \\
\text { Player B was } \\
\text { forced to } \\
\text { accept? }\end{array}$ & $\begin{array}{c}\text { Accepted } \\
\text { or } \\
\text { rejected* }\end{array}$ & Earnings \\
\hline Round 1 & & & & & \\
\hline Round 2 & & & & & \\
\hline Round 3 & & & & & \\
\hline Round 4 & & & & & \\
\hline Round 5 & & & & & \\
\hline Round 6 & & & & & \\
\hline Round 7 & & & & & \\
\hline Round 8 & & & & & \\
\hline Round 9 & & & & & \\
\hline Round 10 & & & & & \\
\hline Round 11 & & & & & \\
\hline Round 12 & & & & & \\
\hline Round 13 & & & & & \\
\hline Round 14 & & & & & \\
\hline Round 15 & & & & & \\
\hline
\end{tabular}

Total Earnings for All Rounds

*Remember, a rejected offer means both you and Player B earn zero for that round. An accepted offer means that you earn the pie minus what was offered to Player B.

\section{Instructions (Player B)}

You will be a Player B in this experiment. You and a randomly assigned Player A will have the opportunity to earn some money. In this experiment, there is an amount of money called the "pie." Player A will offer some amount of the pie to an anonymous Player B. The amount offered can be in increments as small as 1 cent. If Player B accepts the offer that Player A makes, then Player B will receive that amount, and Player A will get the amount of the pie minus the amount offered to Player B. If Player B rejects the offer that Player A makes, then both Player A and Player B will receive zero and the pie will be returned to the experimenter. Again, if Player B accepts the proposed division of the pie, then the players will receive that division, but if Player B rejects the proposed division of the pie, then both players will receive nothing. Both Player A and Player B will know the size of the pie at the time to make decisions.

What was just described above is round 1 of this experiment. The experiment will actually consist of several rounds. Once the first round is over, all Players A will be reassigned to different Players B. All Players A will remain Players A and all Players B will remain Players B. You will never be re-matched with the same individual in future rounds. The size of the pie will change in each round. The pie may be smaller or larger in any given round than it was in the previous round, but it will never be the same size.

On the backside of these instructions is your decision sheet for the experiment. A pre- 
set number of rounds have been included, although the experimenter may or may not conduct that number of rounds. The experimenter will handle the exchange of messages from Players A to Players B by use of message slips of paper. At the beginning of a round, the experimenter will hand to Player A a message slip of paper with the size of the pie (for that round) on it. At that point Player A will record the size of the pie on his/her record sheet, and his/her offer to Player B will also be recorded on the message slip. The experimenter will then collect the offers from Players A and randomly distribute them to Players B. You (as a Player B) will then receive one of these offers, but you will not know which Player A made that particular offer to you. You will then record the size of the pie, and the Player A offer on your decision sheet, and then you will make an accept or reject decision. You will record this decision on your decision sheet (back side of this page) as well as record it on the message slip. Once finished, the experimenter will then collect the message slips and return each one to the appropriate Player A so that Player A can record your accept/reject decision (identification numbers ensure that your accept/reject decision is returned to the Player A who made you the offer). At that point, round 1 is finished, and Players A and B can record earnings for round 1.

All subsequent rounds will be conducted similarly. Again, the only difference will be the size of the pie, and you are never paired with the same individual more than once. Your total earnings for the experiment are the sum of your earnings for each round.

If you have any questions, please raise your hand so that the experimenter can clarify any and all things for you prior to the start of the experiment.

\section{Decision Sheet: Player B}

The shaded column is a hypothetical question that we would like you to answer. Your earnings for any given round do not depend on this answer at all. It is merely to provide additional useful information to the experimenter.

\begin{tabular}{|l|l|l|l|l|l|}
\hline & Pie size & $\begin{array}{c}\text { Amount } \\
\text { offered } \\
\text { from } \\
\text { Player A }\end{array}$ & $\begin{array}{c}\text { What is the } \\
\text { minimum } \\
\text { you would } \\
\text { accept for } \\
\text { this pie size? }\end{array}$ & $\begin{array}{c}\text { Accept } \\
\text { or } \\
\text { reject* }\end{array}$ & Earnings \\
\hline Round 1 & & & & & \\
\hline Round 2 & & & & & \\
\hline Round 3 & & & & & \\
\hline Round 4 & & & & & \\
\hline Round 5 & & & & & \\
\hline Round 6 & & & & & \\
\hline Round 7 & & & & & \\
\hline Round 8 & & & & & \\
\hline Round 9 & & & & & \\
\hline Round 10 & & & & & \\
\hline Round 11 & & & & & \\
\hline Round 12 & & & & & \\
\hline Round 13 & & & & & \\
\hline Round 14 & & & & & \\
\hline Round 15 & & & & & \\
\hline
\end{tabular}

Total Earnings for All Rounds

*Remember, a rejected offer means both you and Player A earn zero for that round. An accepted offer means that you earn what the offer is, and Player A earns the pie minus what was offered to you. 
Experimenter fills in SIZE OF PIE before handing to Player A. Player A fills in ID\# and offer to Player B. Strips are then transferred to a random, anonymous Player B. Player B records the size of the pie and his/her decision to accept or reject. Player B then circles either Accept or Reject and, when all Players B have made their decisions, the experimenter transfers the message strip back to the appropriate Player A (using ID\#). Round is then finished.

Player A ID\#

SIZE OF PIE

Amount Offered to Player B

Accept or Reject (Player B will circle one) 


\section{NOTES}

1. In the Dictator Game, proposers are predicted to keep all of the pie.

2. For a survey of the experimental economic research on bargaining behavior, see Roth (1995).

3. The experiment is based on those used in Dickinson (2000). Loosely speaking, the framework used is a test of the fairness theory in Rabin (1993).

4. 1 typically award a small number of extra-credit points for top experimental earnings. This process is not perfect because students often believe that a few points will not affect their grades. It is often more meaningful to explain how much the extra-credit points might affect the grade on one midterm exam because this will likely make the extra-credit points more salient for the students. There are bound to be discontinuities in the payoffs to the students, however, and so the classroom data will still contain noise. This is somewhat less of a concern if your institution grades on the plus/minus system (used by Utah State University for students who generated the data shown in this article).

5. I have not yet pre-announced the pie-size distribution in my experiments, but a referee noted that when the actual dollar amount of the pie is somehow converted into points or a lesser amount of money, the students may not know whether $\$ 50$ is a large, medium, or small pie size in the experiment. I will probably employ this useful suggestion in the future. Pre-announcing the pie-size distribution might also generate a more significant downward trend than shown in Figure 2, although this last point is uncertain.

6. It is relatively easy to create your own pattern within the classroom for proposers and responders (e.g., proposers in the first five rows numbered from right to left). This pattern makes it easier to hand out message slips to different responders in each round, and it facilitates returning the slips to the appropriate proposer.

7. A column could easily be added to the decision sheet in the appendix for Player B (the responder) that would require the identification number of the Player $A$ to be recorded in each round. This would allow the instructor to check more easily for inconsistencies in the data entries. I typically use a preconceived pattern of matching proposers and responders in each round, which can serve the same purpose because the specific pairings are thought out in advance.

8. Two other interesting examples of ultimatum-type situations were suggested by a referee. One is bilateral trade negotiations breaking down and the gains from trade being lost. A second example is the failure to pass legislation because of political coalitions falling apart over the failure to agree on the distribution of economic rents.

9. The structure of the classroom game does not satisfy all of the assumptions of the Rabin (1993) game theoretic model (e.g., our game is a sequential-move game, whereas Rabin's assumes simultaneous moves). This difference, however, does not limit the ability to use Figure I as a predictor of behavior. It is somewhat analogous to the use of classroom market 
experiments-- commonly used among experimental economists at least. These market experiments-half the students are suppliers and half are demanders of a fictitious good for which the instructor has given the students either a cost or willingness-to-pay figure-violate several of the assumptions of the perfectly competitive model taught in introductory economics courses. Nevertheless, the classic supply and demand diagram is inevitably used ex post to show the theory's (usually impressive) predictive powers.

10. This game is a very simplified version of Rabin's theory. The simplified version is still useful for classroom purposes, but the reader is directed to Rabin (1993) for a complete description of the theory.

\section{This observation was noted by an astute referee.}

12. Specifically, a low relative price of giving in Andreoni and Miller's (2001) experiment occurs when offering a token (from a fixed-token endowment) to the responder raises the responder's payoff by more than it lowers the proposer's payoff. For example, each token offered to the responder may increase the responder's payoff by three, whereas it lowers the proposer's payoff by only one. In this article, the relative material cost of giving is always one, but a smaller pie size is considered to reduce the absolute material price of giving.

13. Note that in Table I a significant number of offers of over 50 percent of the pie are rejected. I have noticed this in this classroom game, but never in the same research experiment game. If anything, this highlights the importance of motivating student behavior with points or money. The extra-credit points offered in my experiment may have provided little motivation for some students, but other responders appeared to attempt strategic rejections in order to gain more than 50 percent of the pie.

14. Examples of other hypotheses that could be useful for classroom discussion are a hypothesis of equally splitting the pie as a simple rule-of-thumb, and the notion that responders in simple bargaining behave as if a minimum percentage threshold is invariant to the size of the pie (Ochs and Roth 1989).

15. The results from five different classroom experiments conducted during the 1999-2000 academic year vaied somewhat. Sometimes the fitted-line relationship shown in Figure 2 had a statistically insignificant slope, but I have not yet generated data from a classroom in which offers (either ultimatum or hypothetical dictator) or hypothetical minimum demanded amounts were statistically significantly positively related to the pie size (using a basic OLS regression to fit the line). Sometimes, in other words, students behave as though the pie size does not affect behavior at all. This could suggest either that for such classes, the reciprocal kindness theory does not predict behavior well, or the pie sizes do not grow large enough for the predictions to be home out.

16. A referee conducted this experiment in class and noted that the most (least) generous proposers were those with the highest (lowest) grades in class. As such, "wealth" effects may be important determinants of one's concept of fairness toward others. 
17. The content of the short quiz is unimportant. The simplest procedure (Ball and Eckel 1998) involves asking questions with numeric answers, and then simply adding the answers together and choosing the high scorers in this manner. It not only is quick but also controls for the potential to select the (perhaps) more intelligent students as the proposers.

18. Several authors confirm that merit matters. See, for example, Dickinson and Tiefenthaler (2002), Hoffman and Spitzer (1985), Guth (1988), and Burrows and Loomes (1994).

19. This extension was suggested by an anonymous referee.

\section{REFERENCES}

Andreoni, J., and J. Miller. 2001. Giving according to GARP: An experimental test of the consistency of preferences for altruism. Econometrica, 70 (2): 737-53.

Ball, S., and C. Eckel. 1998. The economic value of status. Journal of Socio-Economics 27 (4): 495-514.

Burrows, P., and G. Loomes. 1994. The impact of fairness on bargaining behavior. Empirical Economics 19 (2): 201-22.

Dickinson, D. 2000. Ultimatum decision-making: A test of reciprocal kindness. Theory and Decision 48 (2): 151-77.

Dickinson, D., and J. Tiefenthaler. 2002. What is fair? Experimental evidence. Working paper. Utah State University ERI paper \#2000-04.

Forsythe, R., J. Horowitz, N. Savin, and M. Sefton. 1994. Fairness in simple bargaining experiments. Games and Economic Behavior 6 (3): 347-69.

Guth, W 1988. On the behavioral approach to distributive justice-A theoretical and empirical investigation. In S. Maital, ed., Applied behavioural economics, Vol. 11. Brighton, UK: Wheatsheaf.

Guth, W., R. Schmittberger, and B. Schwarze. 1982. An experimental analysis of ultimatum bargaining. Journal of Economic Behavior and Organization 3 (4): 367-88.

Hoffman, E., and M. Spitzer. 1985. Entitlements, rights, and fairness: An experimental examination of subjects' concepts of distributive justice. Journal of Legal Studies 14:259-97.

Hoffman, E., K. McCabe, K. Shachat, and V. Smith. 1994. Preferences, property rights, and anonymity in bargaining games. Games and Economic Behavior 7 (3): 346-80.

Ochs, J., and A. Roth. 1989. An experimental study of sequential bargaining. American Economic Review 79 (3): 355-84. 
Rabin, M. 1993. Incorporating fairness into game theory and economics. American Economic Review 83 (5): 1281-1302.

Roth, A. 1995. Bargaining experiments. In J. Kagel and A. Roth, eds., The handbook of experimental economics. 253-348. Princeton, N.J.: Princeton University Press. 